\title{
Desenho de superfície do ladrilho hidráulico
}

Juliana Bonformagio de Castro ${ }^{1}$

Maria Isabel Imbronito ${ }^{2}$

DOI 10.20396/eha.vil4.3470

O ladrilho hidráulico é um material de revestimento que surgiu a partir da invenção do cimento Portland, matéria-prima utilizada em sua fabricação. Há registros de que, em 1859, Étienne Larmande criou a técnica de produção de ladrilho hidráulico em Viviers, na França, e que a técnica se disseminou pela Europa ${ }^{3}$. O processo foi aperfeiçoado na fábrica Guilhon-Barthélemy, em Avignon, por Felix Guilhon, e alcançou êxito na conhecida fábrica Garret Rivet y Cia, em Barcelona, Espanha. Segundo Navarro e Morán (2010), o ladrilho hidráulico foi oficialmente apresentado pela empresa Garret Rivet y Cia na Exposição Universal de Paris de 1867. Na época, foi considerada uma técnica inovadora para confeccionar um revestimento decorativo e de grande durabilidade.

O ladrilho hidráulico foi criado para revestir e decorar paredes e pisos. Assim, além de ser considerado um elemento construtivo do edifício, o ladrilho é entendido como arte aplicada, devido à conjunção de sua utilidade (material de revestimento) com a superfície decorada que possibilita variações de desenhos, cores e texturas. Sua produção, difundida no final no século XIX e início do século XX, coincide com os movimentos Arts and Crafts, Art Nouveau e Art Déco, que buscavam a renovação das artes e sua aproximação ao processo industrial. As empresas fabricantes de ladrilhos, como a catalã Escofet, Fortuny i Cia, contrataram artistas e arquitetos inseridos nos movimentos artísticos para desenhar as peças de ladrilho hidráulico ${ }^{4}$. Esta aproximação com movimentos artísticos do período terminou por influenciar, a longo prazo, os desenhos de superfície dos ladrilhos (Figura 1). É possível observar, através da genealogia dos desenhos pertencentes aos movimentos artísticos citados, a combinação de avanços estilísticos modernos com a retomada de temas e padrões de épocas passadas, conforme observa-se na Figura 2, que contém peças de ladrilho hidráulico fabricado na empresa Dalle Piagge em janeiro de 2019.

\footnotetext{
1 Mestre em Arquitetura e Urbanismo pela Universidade São Judas Tadeu (USJT) - Bolsista Capes.

2 Doutora em Arquitetura e Urbanismo pela Universidade São Paulo (FAU - USP).

3 Navarro, Morán, 2010.

4 Alguns artistas contratados pela fábrica Escofet, Fortuny i Cia foram: Lluís Domenech i Montaner, Josep Puig i Cadafalch, Alexandre de Ríquer, Josep Pascó, Rafael Masó, Martín Almiñana, Josep M. Pericas e Enric Moya, conforme site da empresa Escofet (www.escofet.eu)
} 
A produção do ladrilho hoje, em algumas fábricas, ocorre de forma muito similar àquela que ocorria no século XIX, sofrendo apenas alterações na qualidade dos materiais e na introdução de prensas automáticas. Em outras palavras, o ladrilho hidráulico é, até hoje, um produto manufaturado feito em série a partir da utilização de moldes. Com o auxílio dos moldes, compartimentos estanques são preenchimento por massa pigmentada colorida formando desenhos, que posteriormente irão se compor a partir do assentamento das peças em modulação (Figura 2). Pode-se ainda dizer que o desenho de superfície do ladrilho hidráulico, com características determinadas por seu processo de fabricação, contém princípios compositivos que são determinados pela possibilidade de combinação de peças repetidas para formar desenhos maiores, o que determina uma relação entre a peça, enquanto fragmento de um padrão, e a totalidade do desenho, ambos concebidos dentro de uma lógica industrial da série com repetição.

Tanto o aspecto artístico do desenho de superfície como os princípios de composição utilizados para a combinação das peças, enquanto elementos determinantes do desenho de superfície do ladrilho hidráulico, foram analisados nesta pesquisa.

Para análise artística do desenho de superfície, utilizou-se como base o campo da história da arte. Nos três movimentos artísticos citados (Arts and Crafts, Art Nouveau e Art Déco) há a presença de arte aplicada, uma vez que o valor artístico tem como suporte um objeto que se presta a um uso e cuja produção está associada à indústria. O ladrilho hidráulico ocorre em meio a uma efervescência do desenvolvimento industrial, na qual muitos produtos foram acusados de serem produzidos de forma massificada com perda da qualidade estética e do valor artístico.

$\mathrm{O}$ Arts and Crafts, foi um movimento que surgiu na Inglaterra e ofereceu importante resistência ao avanço da produção industrial desqualificada, opondo-se à massificação dos produtos e à exploração do trabalho operário, defendendo o resgate das artes manuais, da valorização do artista (artesão) e do produto confeccionado. O movimento criticava a perda da qualidade artística relacionada à exploração do trabalhador em um ambiente alienante.

O questionamento acerca da linguagem artística já se apresentava antes do surgimento do Arts and Crafts. Segundo Pevsner (1968), a busca por um estilo na arquitetura, na arte e nas artes aplicadas teve início com uma revisão de movimentos artísticos anteriores, sendo a familiaridade com diversas linguagens uma herança do período historicista. Em 1830, Owen Jones (1809-1874) iniciava os estudos de ornamentos de períodos artísticos passados ${ }^{5}$, da Antiguidade à arte inglesa 


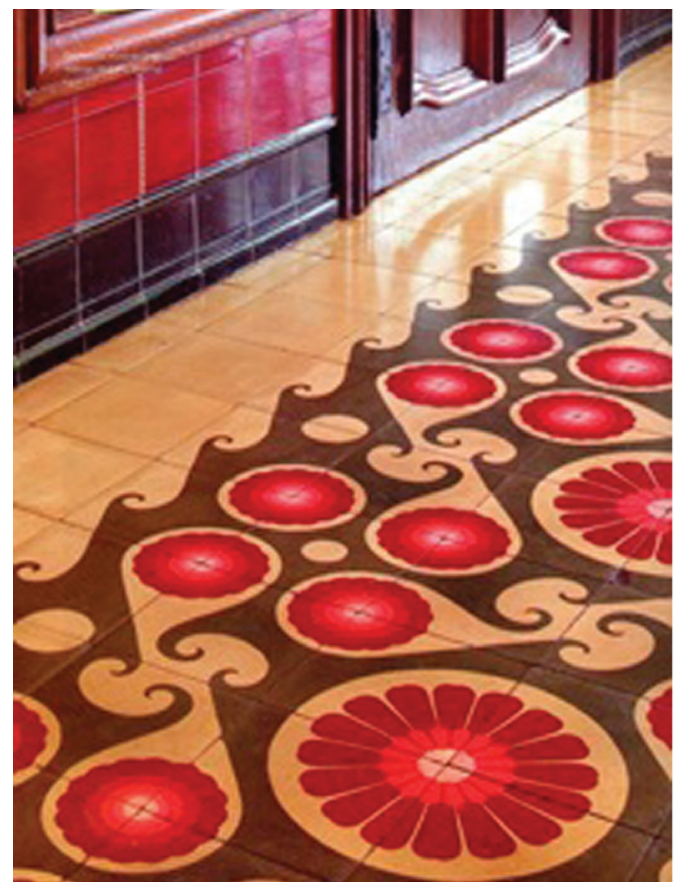

[Figura 01] Ladrilhos hidráulicos Escofet, Fortuny y Cía, pelo arquiteto José Rafols, no catálogo de 1916.

Fonte www.escofet.eu (2017).

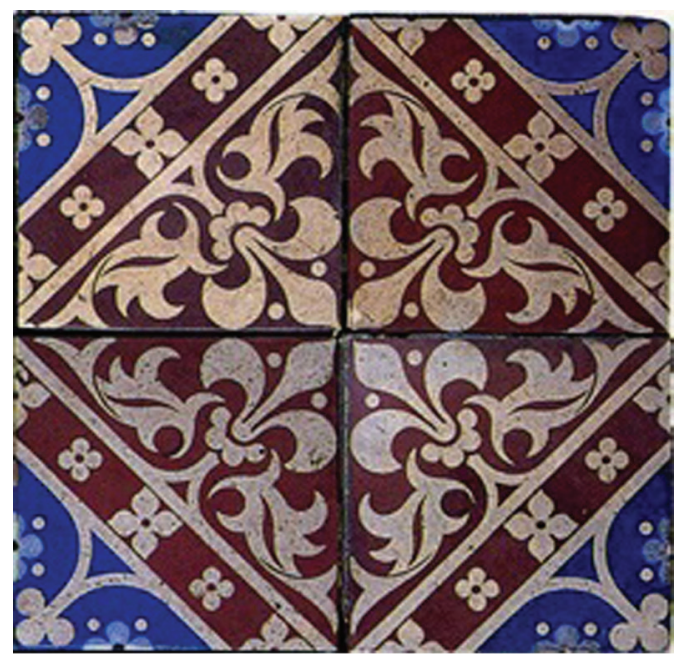

[Figura 03] Ladrilhos encáusticos com temas medievais desenhados por Pugin e produzido por Minton, 1850.

Fonte: httpwww.voysey.gotik-romanik.dePugin\%20 ThumbnailsThumbnails.html

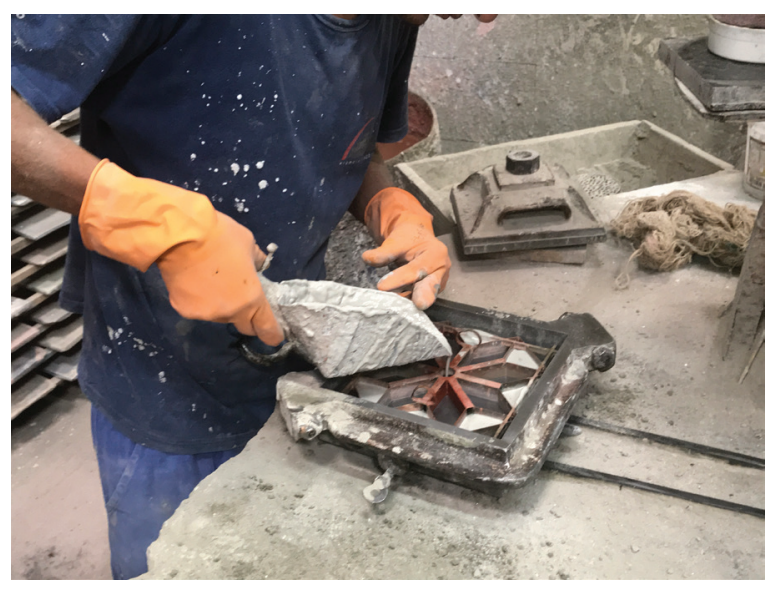

[Figura 02] Ladrilheiro despeja pigmentos nos compartimentos do molde para compor a camada superficial. Fábrica Dalle Piagge SP , jan 2019. Fonte Autoria própria.

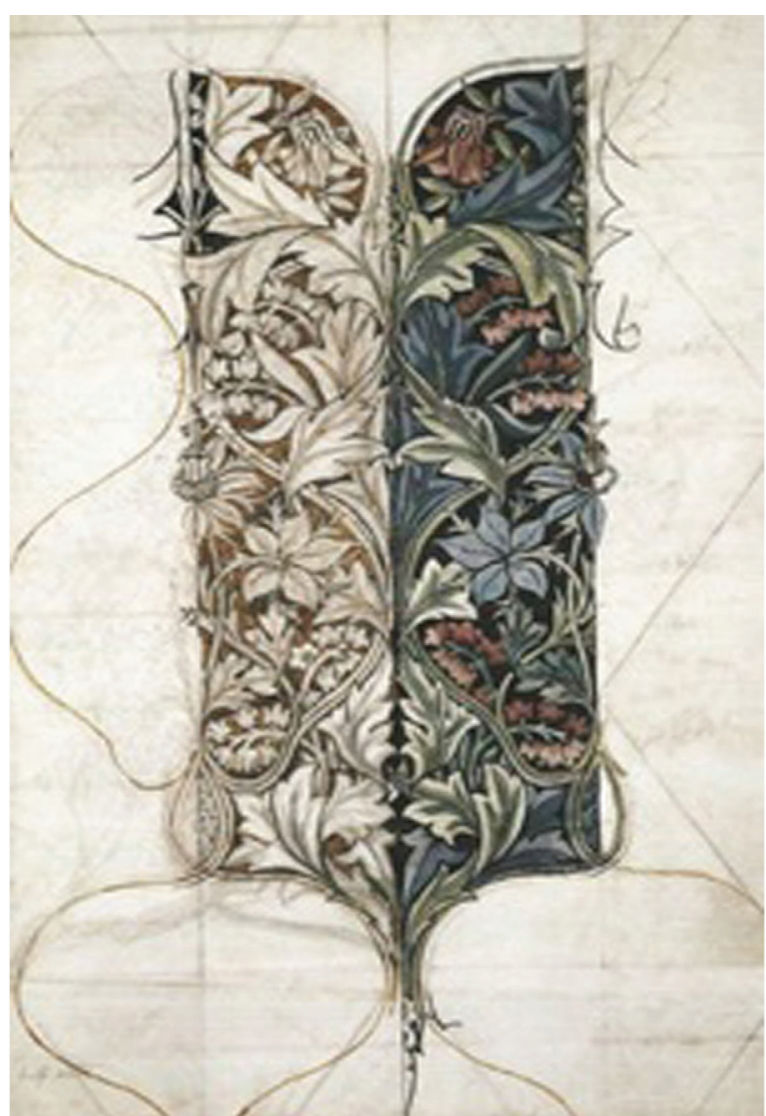

[Figura 04] Aquilégia (lápis, caneta, tinta aquarela) tecido, 1876. Folhagem se espelha, padrão repetitivo, como os desenhos de ladrilho hidráulico. Fonte Livro "William Morris - Diseños Decorativos" - 2011. 
de seu tempo, sendo reconhecido pela grande repercussão de seu trabalho com o livro Gramática do Ornamento (1856), que influenciou as criações dos arquitetos e designers na busca por uma linguagem nova.

Estas convicções também estavam presentes em contemporâneos de Jones, como o arquiteto Augustus Pugin (1812-1852). Devido à sua conversão a religião católica, Pugin valorizava principalmente o período medieval e o gótico inglês, utilizando ornamentos na arquitetura e nas artes aplicadas. Uma das contribuições de Pugin foi reavivar a técnica medieval do ladrilho encáustico (cerâmica queimada) juntamente com o ceramista Herbert Minton (1793-1858) . A parceria estimulou a empresa Minton \& Company a produzir com sucesso ladrilhos cerâmicos com temas medievais muito próximos a ladrilhos medievais originais (Figuras 3), utilizando tonalidades diferentes para formar desenhos na superfície da peça.

Pugin entusiasmou muitos arquitetos e artistas do século XIX, e seu trabalho repercutiu nos desenhos de seus contemporâneos ${ }^{7}$ - entre eles Owen Jones e William Morris -, ao publicar seu livro Floriated Ornament (1849), que continha reflexões sobre a influência das espécies botânicas nos elementos decorativos da Idade Média. Pugin já defendia reinterpretar a natureza de modo estilizado e com formas geométricas, e não reproduzindo suas formas. O livro de Pugin influenciou Jones, que finalizou a Gramática do Ornamento com esquemas de ornamentos florais contemporâneos, o que, por sua vez, motivou os trabalhos posteriores de Morris ${ }^{8}$.

Expoente do Arts and Crafts, William Morris (1834-1896), inspirado em ideais do escritor John Ruskin (1819-1900), estava insatisfeito, juntamente com seus contemporâneos, com relação à banalização da criação nos setores industriais, e passou a se dedicar às oficinas como meio de produção, apostando no retorno do homem ao ofício e à arte para a melhoria da qualidade do produto de consumo e originalidade do desenho das peças. Além das ideias de Morris virem de encontro ao modo de produção do ladrilho hidráulico e também à sua condição de arte aplicada, os trabaIhos que Morris tiveram grande importância pois serviram para sistematizar padrões que, ao serem repetidos e espelhados nos processos mecânicos de fabricação, possibilitaram composições de arranjos fluidos e complexos nos diversos produtos da empresa à qual ele fundou - Morris, Marshall, 
Faulkner and Company ${ }^{10}$-, como tapeçaria, papéis de parede, azulejos e vitrais (Figuras 4). Muitos desses padrões gráficos eram concebidos para que fragmentos do desenho se encaixassem formando um desenho maior e contínuo, importante prerrogativa para pensar os padrões decorativos para a indústria. A continuidade do desenho ocorre no encaixe do fragmento ou padrão elementar, cujo desenho precisa contemplar a repetição ou espelhamento para se completar. Também está presente a complementariedade e formação do desenho através da relação figura-fundo, nas quais os desenhos são obtidos em processos mais econômicos com apenas duas cores.

Anos depois, o Art Nouveau surge como resposta original e representativa, do ponto de vista artístico, da produção material proveniente do embate sobre o uso da máquina ${ }^{11}$. O movimento Art Nouveau contribuiu para a problematização da importância da expressão do artista e sua inserção no processo industrial moderno. Esta expressão do artista foi associada por Henry Van de Velde (1863-1957) à "força da linha", em que a linha gestual da criação do artesão transparece nos artefatos $^{12}$. A valorização de elementos da natureza e sua representação não realista, feita através de traços estilizados, sinuosos e contínuos, está relacionado a esta "linha", reelaborada através de processos de estilização e simplificação, tanto adaptando-se para compor o desenho de objetos, como valendo-se de repetições e entrelaçamentos para a combinação em padronagem contínua. Aqui também se notam paralelos com os desenhos de superfície de ladrilho hidráulico (Figura 5).

Algumas manifestações do movimento Art Nouveau se encaminharam para desenhos mais geometrizados (em Clasgow, Viena e na Escandinávia), mantendo sempre uma atitude decorativa que assume a geometria como tema, direcionando-se a uma adaptação do desenho dos objetos à produção industrial. Em meados dos anos 1920, acrescentam-se novas preocupações e princípios, que são comumente vinculados ao movimento Art Déco, como a simplificação dos objetos para a reprodução em escala industrial. O ladrilho hidráulico também permeia esta vertente artística ligada à indústria e caracterizada pelo tema do progresso, da tecnologia e em diálogo com a arte de vanguarda, trazendo para sua superfície novos desenhos mais angulares e tridimensionais, além de desenhos figurativos que representam o progresso (Figura 6).

\footnotetext{
10 MEGGS; PURVIS, 2009.

11 BENEVOLO, 2004.

12 FRAMPTON, 2012.
} 
Composição modulada do desenho de superfície do ladrilho hidráulico

O desenho de superfície do ladrilho hidráulico é aplicado a peças elementares produzidas em série pela indústria, e que se juntam no assentamento formando grandes superfícies. Para elaborar o fragmento do desenho que consta na peça de ladrilho hidráulico, é necessário atentar-se ao princípio combinatório das peças. Esta parte do texto é dedicada à análise da relação entre a peça isolada e os modos de arranjo da peça elementar - fragmento, rotação, espelhamento, repetição -, para formar desenhos complexos com base em combinações moduladas.

Os ladrilhos hidráulicos que serviram de exemplo a estas análises foram extraídos do catálogo de ladrilhos hidráulicos da empresa Casa Franceza, localizada em São Paulo, e que esteve vigente até 1940. A partir do conjunto de peças constantes no catálogo, nota-se a presença de desenhos com influência Art Nouveau e Art Déco, e as diferentes possibilidades de disposição das peças, definidas no momento do assentamento.

O desenho da peça a ser confeccionada é determinado pelas limitações advindas do molde, que tem a capacidade de configurar o desenho por preenchimento de campos de cor. Os compartimentos estanques do molde recebem o despejamento de massa de cimento pigmentada, compondo formas e ilusões de linhas. O nível de detalhe do desenho fica restrito às possibilidades físicas do molde, que determina as barreiras para o derramamento do pigmento e acuidade necessária para o despejo manual do material em cada repartição. Outro objeto que determina a dimensão e o formato da peça é a moldura. A moldura recebe o molde e determina o formato e o tamanho da peça.

Para realizar estes estudos, buscou-se referencial teórico no campo do desenho de superfície, desenvolvendo-se uma metodologia de análise fundamentada em autores reconhecidos. As análises enfocam três aspectos: o desenho da peça unitária; o arranjo ou combinação de peças no assentamento com base na repetição modulada; e o efeito visual do desenho.

Na primeira parte - o desenho da peça unitária -, é analisado o desenho de uma única peça (um ladrilho de $20 \times 20 \mathrm{~cm}$ ). Este poderá constituir uma totalidade, um fragmento ou conter uma repetição de desenhos menores. Chamou-se o desenho completo de "unidades de forma"13. Os estudos revelaram: unidade de forma correspondente à peça (Figura 7); unidade de forma em repetição na peça; e fragmento da unidade de forma presente na peça. Quando ocorre na peça o fragmento da unidade de forma, a unidade de forma irá complementar-se nas peças seguintes através de: con-

13 WONG (2010, p. 51). 


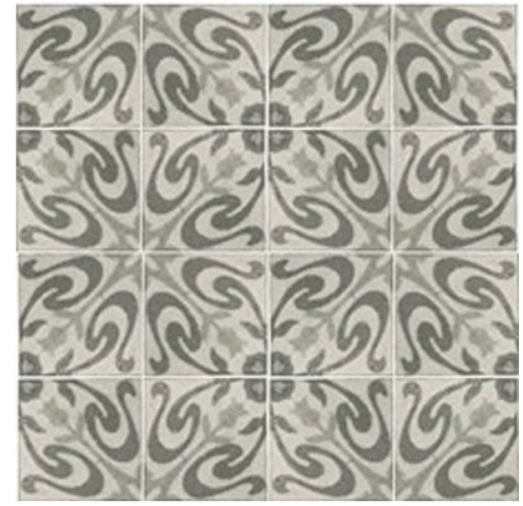

[Figura 05] Linhas orgânicas e onduladas, típicas Art Nouveau. Complementam-se com peças lado a lado.

Fonte Montagem a partir do catálogo da Casa Franceza, entre 1917 a 1940, peça n. 75 (arquivo pessoal).

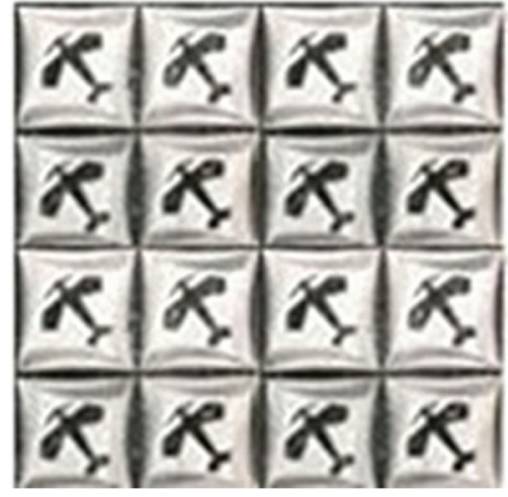

[Figura 06] Imagem figurativa, representando o progresso e formas angulares e mais geometrizadas.

Fonte Montagem a partir do catálogo da Casa Franceza, entre 1917 a 1940, peça nº 70 (arquivo pessoal)
[Figura 08] Desenho da peça se relaciona com assentamento, a partir de combinações diferentes, como repetição e rotação. Fonte Combinações a partir das peças n. 98 e n. 97 (arquivo pessoal).

\section{Repetição}

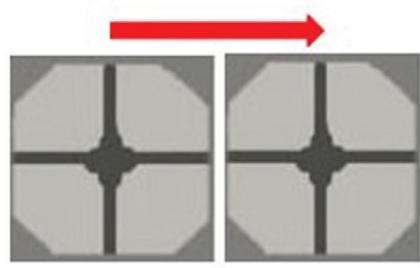

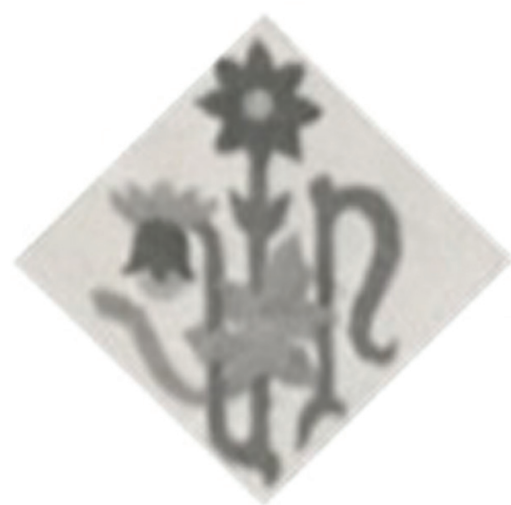

[Figura 07] Unidade de forma, correspondente à peça e seu desenho.

Fonte Peça n. 84, do catálogo da Casa Franceza, entre 1917 a 1940 (arquivo pessoal).

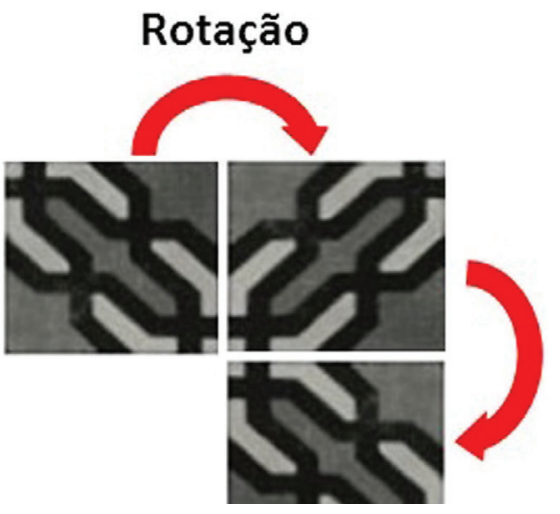

[Figura 09] Combinações a partir de modo de assentamento por espelhamento e combinação alternada.

Fonte Montagem das combinações a partir das peças n. 47 e n. 36 (arquivo pessoal).

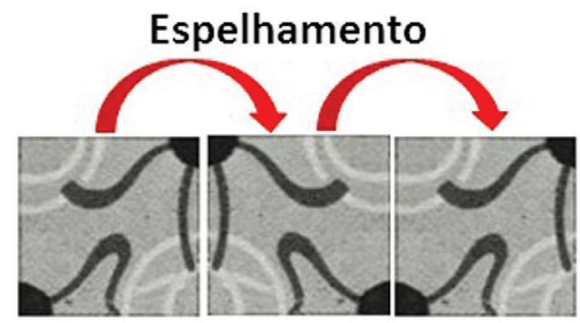

Combinação Alternada

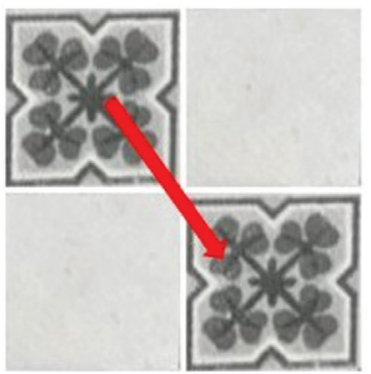


tinuidade por alinhamento, continuidade por rotação, continuidade por espelhamento.

A segunda análise foi feita a partir do Arranjo ou combinação de peças no assentamento, com base na repetição modulada, que define o arranjo corresponde ao modo de combinação de peças, formando desenhos de composição modulada a partir da junção do módulo-base, que é a peça isolada.

O desenho da peça se relaciona com o modo de assentamento, porém uma mesma peça pode ser assentada em combinações diferentes, formando composições diferentes. $O$ mesmo desenho na peça de ladrilho pode possibilitar uma ou mais combinações, e essas combinações são determinadas por quatro modos: repetição, rotação, espelhamento e combinação alternada (Figuras 08 e 09).

A última parte da análise trata do resultado gráfico ou efeito. A partir do assentamento conjunto das peças, são observados diversos tipos de efeitos visuais criados por estas combinações de peças, sendo possível ter alguns fatores que interferem no efeito, tais como: cores, tonalidades e figura-fundo; efeito de linha, direção (diagonal, reta vertical e reta horizontal), entrelaçamento e superposição, ilusão de tridimensionalidade, padronagem por multiplicação simples e composta, ambiguidade na combinação dos desenhos, ambiguidade da escala do desenho final, ambiguidade de figura-fundo, efeito geral de caleidoscópio.

Estas são algumas possibilidades de análises de critérios de análise própria da configuração do desenho bidimensional apresentada enquanto superfície decorada do ladrilho hidráulico do catálogo da empresa Casa Franceza.

As análises não se fecham nestas possibilidades, pois as capacidades de análises das configurações do desenho das peças, arranjo (composição modular) e resultados gráficos (por percepção visual) mapeiam vastas combinações. Criando as possibilidades de estudo destas combinações enquanto elementos de forma compondo desenhos bidimensionais, fragmentados e/ou completos. 
Referências Bibliográficas

ARNHEIM, Rudolf. Arte e percepção visual: uma psicologia da visão criadora. $1^{\circ}$ Edição Brasileira. Tradução de I.T. De Faria. São Paulo: Cengage Learning, 2015.

ARNHEIM, Rudolf. Intuição e intelecto na arte. Tradução de J.L. Camargo. São Paulo: Martins Fontes, $1^{\circ}$ Edição Brasileira. 1989.

BARBOSA, Ruy Madsen. Descobrindo Padrões em Mosaico. São Paulo: Atual, 1993.

BENEVOLO, Leonardo. História da arquitetura moderna. $3^{\circ}$ Edição. Tradução de Ana M. Goldberger. São Paulo, SP: Perspectiva, 2004.

COLQUHOUN, Alan. La arquitectura moderna: una historia desapasionada. Barcelona: Gustavo Gili, 2005.

FILHO, João G. Gestalt do objeto: sistema de leitura visual da forma. $2^{\circ}$ Edição. São Paulo: Escrituras Editora, 2000

GALLAS, Alfredo O. G.; GALLAS, Fernanda Disperati. Art Déco: Europa, EUA, Brasil. São Paulo: Editora do Autor (Gallas \& Disparati), 2013. Patrocínio Itaú.

JONES, Owen. Gramática do Ornamento. São Paulo: SENAC, 2010.

LACE, Maria A. Mobilização das formas de pensamento matemático no estudo de transformações geométricas no plano. Pontifícia Universidade Católica de Minas Gerais. Curso de Especialização (Mestrado) em Ensino de Ciências e Matemática. Belo Horizonte, 2008. Disponível em: < http://www.biblioteca.pucminas.br/teses/EnciMat_LageMA_1. pdf> Acesso em: Mar. 2018.

LIMA, Carlos R. B. Revestimentos hidráulicos. Entre arte e tecnologia: passado, presente e novas possibilidades. Universidade de São Paulo - Instituto de Arquitetura e Urbanismo/ São Carlos. Curso de Especialização (Mestrado) em Arquitetura e Urbanismo. São Carlos, 2015. Disponível em: <http://www.teses.usp.br/teses/disponiveis/102/102131/ tde-08032016-101916/pt-br.php> Acesso em: Ago. 2019.

LUPTON, Ellen; PHILLIPS, Jennifer C. Novos fundamentos do design. Tradução de C. Borges. São Paulo: Cosac Naify, 2008 .

MECCS, Philip B.; PURVIS, Alston W. História do design gráfico. Tradução de Cid Knipel. São Paulo: Cosac \& Naify, 2009.

MANIERI-ELIA, Mario. William Morris y la ideología de la arquitectura moderna. $2^{\circ}$ Edição. Barcelona: Gustavo Gili, 2001. Coleção "CG Reprints".

NAVARRO, Mario Arturo Hernandéz; MORÁN, Hernán S. Bustelo. Puerto Rico: Tiles Designs. Amsterdam: The Pepin Press, 2010.

PEVSNER, Nikolaus. Os pioneiros do desenho moderno: De William Morris a Walter Gropius. $3^{\circ}$ Edição. São Paulo, SP: Martins Fontes, 2002.

RUBIM, Renata. Desenhando a superfície. $2^{\circ}$ Edição. São Paulo: Rosari, 2010. Revisão atual.

TSCHUDI-MADSEN, Stephan. Art nouveau. Porto: Inova, 1967.

WONG, Wucius. Princípios de forma e desenho. São Paulo, S.P.: Martins Fontes, 2014.

William Morris - Diseños Decorativos. Paris: Éditions Place des Victoires, 2011. 